\title{
La Pastoral de la confesión en las Conciones de Sto. Tomás de Villanueva*
}

\author{
iv. EL CONFESOR A LA LUZ DE LA DOCTRINA PRECEDENTE
}

En los capítulos anteriores hemos tratado de comprender un poco el mensaje íntimo que Dios dirige al hombre a través de su propia naturaleza humana. Era la primera llamada de Dios, la creación.

Hemos estudiado la obra destructora del pecado, una realidad dinámica que agosta las más bellas energias humaras en la destrucción de las apetencias específicas del hombre.

Veíamos, a continuación, la descripción de un Dios personal que, en su amor salvífico, consagraba su omnipotenica y sabiduría infinitas a la salvación del hombre. Era una acción interna de Dios en el alma que culminaba en la donación del Verbo que se encarna también por amor al hombre y consagra su vida terrestre a la salvación del género humano, y a trazar, de forma visible ante las miradas de los hombres, el camino que debían seguir en su ascensión a Dios y la actitud que debía regular su conducta para con Dios. La Encarnación y Redención, como manifestaciones externas de la acción de Dios en el alma, constituyen el segundo título que, en el amor que se da, obliga al hombre a redonarse como respuesta amorosa.

Veíamos cómo en el Sacramento de la penitencia se continuaban las características de la acción interna de Dios en el alma y de las intervenciones salvíficas de Cristo.

Todo este conjunto doctrinal debe facilitarnos la recta y profunda inteligencia - $y$ éste era su fin- de una serie de frases escogidas, plenamente modernas, que encontramos en las obras del

* Cfro Estudio AGustiniano 10 (1975) $373-400 ; 11$ (1976) 3-44; 195-218. 
sanio sobre el confesor y su misión. Son expresiones que sólo pueden comprenderse en relación con las ideas anteriormente expuestas.

Cristo instituyó el sacramento de la penitencia como prolongación de la misericordia divina a lo largo de los siglos y como llamada constante y permanente al perdón y a la contrición ${ }^{1}$. Es el testimonio externo de la existenica de una gracia que, en la contrición, perdona el pecado. Pero en la concelebración del Sacramento interviene el penitente e interviene también el confesor. Después de la Redención sólo es posible el acceso al Padre en Cristo y con Cristo en la Iglesia ${ }^{2}$. Por voluntad expresa de Cristo el sacerdote es su representante en el Sacramento y también lo es de la Iglesia ${ }^{3}$. He aquí cómo el sacerdote ha de esforzarse por traducir en el lenguaje vivo de las obras, de las actitudes etc., la conducta que Cristo y la Iglesia adoptan con el pecador. Pero a su vez Cristo es el delegado del Padre ${ }^{4}$ y el sacerdote, en la delegación y representación de Cristo, recibe también la representación de la acción interna de Dios en las almas y de la historia de la conducta seguida por Dios con la humanidad pecadora hasta la Redención.

Sin duda alguna, cuanto a continuación diga a propósito de la figura del confesor, podriamos deducirlo con toda rigidez científica de la consideración de la acción interna de Dios. Sin embargo, toda esa belleza de la acción interna de Dios en el alma mediante la gracia se resume y encuentra su perfecta exteriorización en la obra redentora, en la vida mortal del Verbo encarnado, De aquí que Sto. Tomás al contornear con pinceladas maestrás la figura atrayente del confesor fije nuestra atención en Cristo como modelo. $Y$ no crea con esto laguna alguna en su doctrina. En último análisis la acción de la gracia, la conducta del Padre con la humanidad pecadora anterior a la Redención y la norma que Cristo nos trazó en su vida mortal son idénticas.

También hemos de notar que, como regla general, no encontraremos en sus obras la aplicación concreta. El, partiendo de las ideas fundamentales $y$, sobre todo, de la meditación profunda de la

1. In Dom. IV Adv, c. VI n. 1-6, t. I, 132-137.

2. In fer. IV Cinerum c. II n. 20, t. I, 130-131; In fer. II post Dom. IV Quadrag. c. II n. 14 , t. II, 99.

3. In Dom. III Quadrag. c. I n. 4-5, t. II, 5-6; In Dom. in Palmis c. II n. 7, t. II, 222.

4. In Dom. III Quadrag. c. I n. 4-5, t. II, 5-6. 
vida apostólica de Cristo, fija los límites generales dentro de los que debe encuadrarse la acción del sacerdote. Ha sabido apreciar la gran dependencia que tales aplicaciones prácticas tienen del elemento humano que se manifiesta en las circunstancias particulares de cada caso y que escapa a los fríos esquemas intelectuales. Por otra parte, y puede constatarse fácilmente en sus obras, es una utopía querer considerar el oficio de juez independientemente del de médico. Aspecto de juez y de médico, unidos en la persona del confesor, son como el binomio que encarna externamente aquel otro binomio de la justicia y misericordia en Dios. Lo misıno que éstas, justicia y misericordia, eran inseperables, asi aquellas dos facetas, juez y médico, van o deben ir siempre intimamente unidas. Todas las obras divinas llevan la impronta de ambas virtudes en una armoniosa, pero misteriosa compenetración. Esta es la armonización y unidad difícil de conseguir entre sus dos aspectos de juez y médico, como origen de una conducta externa que será el signo visible, el sacramento de la divina misericordia justa. Sin duda es una armonización que únicamente la prudencia cristiana, iluminada por la caridad y por un íntimo conocimiento y convencida adhesión al significado y a la misión de su obra, logrará conseguir. Al igual que en el misterio redentor la justicia se cumple, pero como dirigida y envuelta en los velos de la misericordia, así en el confesonario el confesor hace triunfar los derechos del Señor, pero guiado y moderado por la solicitud y la delicadeza del médico para con el enfermo aún débil. Como si la faceta de médico trazara a aquélla otra de juez, el camino que ha de seguir para hacer triunfar plenamente los derechos de Dios evitando toda violencia. Esta es la magnífica armonía, en el mutuo complemento, que quiere ver Sto. Tomás de Villanueva en la conducta externa del confesor. También comprendemos que el Santo nunca, o casi nunca, reclama la atención del confesor sobre el concepto de juez. En el hombre se da una tendencia espontánea a la justicia y severidad. Por eso, él cuida de salvar la validez y eficacia del Sacramento, pero su atención estâ en hacer comprender al confesor que ha de ser médico solícito y generosamente atento con el enfermo, el ministro que en su magnificencia recuerde al Cristo "minister magnificus".

Es una pena que no dirigiera conferencia alguna a sus sacerdotes, porque sus rápidas alusiones en las homilias al pueblo fundamentan la esperanza de una concepción tal del confesor, que muy bien podríamos aceptar y ser orientación en nuestro siglo. 
Entre los valores de concepción podemos señalar, en primer lugar, e rechazar toda visión parcial del problema que pudiera plantearse al confesor En sus obras se descubre como una tendencia innata a buscar la sintesis en una visión completa y, por tanto, compleja del problema.

De aquí nace un segundo valor: el de haber integrado el elemento subjetivo en cualquiera de las reflexiones que debían conducirle a una decisión práctica. Ha valorado justamente el elemento subjetivo y, tal vez como reacción, hace hincapié en la necesidad de integrarlo en el elemento objetivo a la hora de dar un juicio moral sobre conductas concretas. Torna una y otra vez a la revalorización de lo subjetivo, que se encarna y se manifiesta en las circunstancias concretas de cada caso concreto. En una palabra, es la revalorización de esa parte humana, de ese algo del hombre que se encuentra en todo acto humano, disimulado entre lo que llamamos objetivo. Ha buscado en la conversión una moral viva, dinámica, de personas. Por eso ha sentido la necesidad de subrayar la parte vital de todo acto. No desprecia lo objetivo. Le concede gustoso el puesto que le corresponde, pero se esforzó en situar convenientemente el elemento subjetivo, vital y quizá tengamos que concluir que da la precedencia a lo subjetivo sobre lo objetivo. Las enunciaciones rígidas y matemáticas de los principios no tienen cabida en su predicación. Las formulaciones excesivamente intelectualizadas excluyen el elemento vital. En el presente contexto reseñamos lo siguiente como dato curioso. En una ocasión, como escapándosele la pluma, concluye tajantemente que quien inmediatamente después de la confesión recae en el pecado no se acercaba con verdadero arrepentimiento a la celebración del sacramento de la penitencia. Pero a línea seguida parece sentirse culpable de traición al propio espiritu que domina su predicación. Recuerda el dinamismo vital de la conversión y comenta: Sin embargo, puede ser que se haya acercado al confesonario guiado de un verdadero espíritu y que la debilidad de la reciente conversión sea superada por la fuerza del vicio contraído anteriormente. El hábito no muere con un solo acto de renuncia ${ }^{5}$.

5. In fer. post Dóm. Passionis c. III n. 3, t. II, 207; In Dom. sexag. c. I n. 2, t. I, 243-244; In fer. III post Dom. IV Quadrag. c. II n. 7, t. Il, 119-120; In fer. VI post Dom. IV Quadrag. c. II n. 4-6, t. II, 110-111.

t. II 
A la luz del dinamisma vital de la conversión, que debe matizar claramente los elementos externos del sacramento, una de las cualidades que debe adornar la conducta del sacerdote, es la de ser una invitación activa y permanente del pueblo cristiano a la concele bración del Sacramento de la reconciliación. El confesor es el representante de la Iglesia de Cristo en la que Dios recibe la confesión del pecador y le otorga misericordiosamente su justo perdón. Pero el sacramento es signo de un espíritu de penitencia ya en acto, que suscitado por la acción interna de Dios, encuentra su consolidación y una especie de autentificación en el sacramento. La acción interna de la gracia divina es continua, ininterrumpida. Hemos participado de la consolación que produce el convencimiento de que Dios acompaña al alma a lo largo del combate de su destierro y que, si desgraciadamente sucumbe, aun en la caída podrá escuchar la llamada misericordiosa de Dios que anhela nuestra conversión más que el mismo pecador. Después de los textos recordados en los ca. pítulos anteriores permítasenos citar aquí uno más:

\footnotetext{
"Dios no cesa de llamar a este desierto del alma pecadora para que se convierta. Desde el día en que comenzó a tener uso de razón hasta su sepultura no cesa Dios de llamarle con gran clemencia. Dios, el ofendido, El mismo ruega e invita..." 6 .
}

Así, pues el carácter de permanente llamada de la acción divina, que es representada y consolidada en la celebración del sacramento de la penitencia, obliga al sacerdote a ser el soldado continuamente pronto al servicio activo de Cristo y de su Cuerpo místico, la Iglesia. A cualquier hora del día puede Dios operar la conversión interna del pecador e impulsar al alma a pedir su consolidación en el sacramento, y a cualquier hora del día el sacerdote debe acoger al alma que el Señor le envía. No hay lugar para un sabio programa de confesionario que excluya toda posible celebración fuera de los límites prefijados. El confesionario no es ninguna oficina. Tal vez se encuentre fatigado y entonces le invitará a las proximidades del pozo de Jacob, en el que Cristo, fatigado de un largo caminar, se sien-

6. In Dom. IV Adv. c. I n. 1, t. I, 114; In Dom. Septuag. c. I n. 2, t. I, 202. 
ta y entabla el delicado diálogo que salva a la Samaritana y la transforma en un apóstol más del Mesias?

Este ser representante de la obra redentora de Cristo y del amor siempre fecundo de la Iglesia exigen del sacerdote mucho más que una disposición, ya implícita ya explícita, de recibir y ofrecer su mejor aportación para conducir a feliz término los deseos de cuantas almas le manifiesten sus ansias de reconciliación con Dios.

Seria una simple nota de urbanidad, la de recibir y tratar bien a los visitantes, a los huéspedes. Y nada más lejos del espíritu de Sto. Tomás de Villanueva que considerar huéspedes a los penitentes. Ciertamente en una concepción que se limitara a "recibir" tal vez pudiera tener cabida la calificación de huésped aplicada al penitente. Mas no la tiene en aquella otra concepción en la que el confesor debe ser un representante activo, como sucede en la predicación del Santo. Sobre el confesor pesa una obligación moral de desarrollar toda una campaña seria y concienzudamente organizada para inducir a las almas a un mejor conocimiento de Cristo a través del sacramento de la confesión. Toda esta actividad del sacerdote, para conducir a las almas a la concelebración del sacramento de la penitencia, es calificada de "invitación", "provocación". Son dos vocablos que nos dan una idea de la fuerza de atracción que debe poseer la actividad sacerdotal.

"Qué gratitud se debe mostrar porque en toda la tierra abundan sacerdotes, que no solamente oyen gustosamente las confesiones, sino que llaman e invitan a los pecadores a que obtengan el perdón" :

En realidad jamás concreta el modo de estimular. Deja la más amplia libertad en la determinación de los medios de crear en las almas esta necesidad. Sin duda estaba convencido de que, recordando que el confesor ha de ser estímulo que mueva a la concelebración del sacramento, el espíritu apostólico del sacerdote sabría determinar los medios más aptos para cada caso. No obstante se ha de conceder un puesto de honor a la predicación. Ella es el gran instrumento al alcance del sacerdote. Su obra homilética puede considerarse como una predicación de la conversión no sólo por la amplitud concedida en sus sermones a los temas relacionados con la

7. In fer. VI poșt Dom. III Quadrag. c. I n. 3-10, t. II, 52-58.

8. In Dom. III Quadrag. c. I n. 5, t. II, 6 . 
conversión, sino porque dan la impresión de ir orientados a acentuar la obra del pecado, el sentimiento del pecado como oposición a los designios divinos y a revelar sus consecuencias. No podemos olvidar esto hoy que se considera generalmente a la pérdida del sentido del pecado como la causa del alejamiento y no aprecio del sacramento de la confesión.

Una segunda cualidad de la acción del confesor será la mansedumbre que brota de la caridad. La acción sacerdotal ha de ser el sacramento, signo visible, de la misericordiosa gracia de la conversión. La magnificencia y la misericordia que nacen al calor de la caridad son las notas más fuertemente distintivas del actuar sacerdotal. $Y$, siempre fundamentado en el principio de que el sacerdote debe responder a la acción interna de Dios en el alma, a la acción de Crișto y a la naturaleza íntima del sacramento de la reconciliación. En cuanto a la acción interna de Dios en el alma sostiene que Dios en ninguna de sus obras se muestra tan claramente Dios como en la misericordia. Es un principio fecundísimo que aplica a! confesor. Este, consciente de su misión, se hará recognoscible precisamente en la mansedumbre con que se esfuerza por imitar a Dios en el perdón:

"Volo autem eum potius peccare per mansuetudinem quam rigorem; ut sit minister magnificus sicut et Dominus magnifice condonat" 9 .

El alma sacerdotal y eminentemente pastoral del Santo lee y medita repetidamente las páginas evangélicas en las que descubre al Verbo encarnado de la misericordia, al médico ansioso de la salud del enfermo, al que buscando su salvación se confunde con los pecadores, al Buen Pastor que va en busca de la oveja perdida, al Señor que perdona mucho a la Magdalena porque ha amado mucho, en una palabra, al padre que, derramando lágrimas de alegría por el retorno del hijo alejado, le tiende sus brazos acogedores y pregona el gran festín al que convida a toda la familia. Finalmente, también recordamos que considera el sacramento de la penitencia como la prolongación de la obra misericordiosa de Cristo sobre la tierra ${ }^{10}$.

La acción del sacerdote comienza fuera del confesionario al

9. In Dom. IV Adv. c. VII n. 2, t. I, 141 .

16 In Dom IV Adv e. VI n. 1-6, t. I, 132-133. 
suscitar por medio de la predicación el ambiente apropiado de conversión exponiendo la naturaleza intima y el verdadero sentido del sacramento. $Y$ sin embargo, en la mentalidad del Santo, parece que la conduc:a seguida por el confesor en la celebración del sacramento es el medio más eficaz para conseguir dicho fin. Porque, si bien es cierto que como sacramento opera "ex opere operato", no es menos cierto que este sacramento más que ningún otro, exige del ministro una acción personal estrechamente ligada a la acción del Espiritu, de manera que puede reforzar o comprometer parcialmente la acción del sacramento.

El confesor inicia su labor con la acogida del penitente. No basta una acogida fundada en la educación. Es preciso que, ya desde el primer gesto, desde la primera palabra, la caridad y la profunda meditación del ministerio sacerdolal ejerzan su papel orientador. Todos sus actos serán una manifestación de la magnificencia y mansedumbre con que Dios le recibe en el tribunal de la propia conciencia. Quiere esa acogida óptima que, aunque viciada en su fundamento, se dispensa a veces en el confesionario a las amistades. Ello requiere una buena dosis de vida espiritual que a su vez se acrecienta en la misma concelebración recta y sincera del sacramento. El constante esfuerzo por imitar la imparcialidad divina que en la llamada personal no establece distinción alguna de clases, 0 de hacerlo se inclina por los más necesitados, es un constante sacrificio que purifica e invita al confesor a escalar nuevas vetas de perfección. Perfección difícil de conseguir pero no por ello menos obligatoria. ¡Con cuánto ardor fustiga el gran Obispo Limosnero la codicia que a veces mueve al sacerdote a buscar el aumento de sus ingresos en la misma celebración de los sacramentos! Las alusiones de sus homilias permiten pensar en un ambiente que en su tiempo había alcanzado una cierta difusión. Son alusiones llenas de dolor e inflamadas en el celo por la causa del Señor:

“¿Quién predica hoy y oye confesiones sin tener muy presente el premio temporal? Son muchos los que aceptan el canonicato o aspiran a contarse entre los clérigos para participar de los réditos del altar. El Señor habla por boca del profeta Malaquías (1,40). "Oh, si alguno de vosotros cerrara las puertas y no encendiérais en vano el fuego de mi altar! No tengo en vosotros complacencia alguna, dice Yahré, no me son gratas las ofrendas de vuestras manos". Se venden los beneficios con rebuscadas maneras y temo que se 
vendan tambien los sacramentos, porque he oído que algunos exigen dinero por la celebración del sacramento de la extrema unción. iOh Pedro, on Pablo, qué dolor experimentariais, y cómo gemiriais si viéraís cuanto acontece hoy en el mundo!" "1?.

Sin duda el dinero ejerce un gran influjo en la distinción de los pecadores y santo Tomás de Villanueva es irrecanciliable e inflexible en cuanto a la distinción de los penitentes por razones humanás. Sus recriminaciones, fuertes ya en sí mismas, impresionan más porque van encuadradas en un contexto de mansedumbre y benignidad. Son contrasies fuertes que nos indican la viveza de los sentimientos del Santo. Al comentar el relato evangélico en el que Jesús expulsa del tempio a los cambistas, a los ricos, con el flagelo, mientras que a los vendedores de palomas, a los pobres, les ordena "quitad de aquí todo eso" (Juan 2,16 ), escribe:

"...no os prohibo que vendáis palomas, os prohibo que to hagáis en el templo, fuera del templo podéis continuar vuestro negocio. $\mathrm{jOh}$ juicios de Dios, cuán dístintos son de los juicios de los hombres! A los pobres, a los humildes "mitte iudicium et cum mansuetudine"; pero a los ricos y potentados "iudicium rigurosum et cum flagellis": "Pues los pequeños hallarán misericordia, pero los poderosos serán poderosamente atormentados (Sap. 6,9). El mundo, en cambio, obra a la inversa. En él la justicia no existe sino para con los pobres; los castigos sólo son usados con los pobres. $\mathrm{Pa}-$ guen los pobres al instante o sean castigados. Pero lo que es aún más doloroso es que también en la Iglesia se reservan las penitencias graves para los pobres, mientras que a los ricos se les imponen las leves o ninguna..."

Y continúa buscando una imagen más expresiva que el mismo vocabulario. Es una fábula:

\begin{abstract}
"Quiero expresar esto mismo mediante una fábula. Es la siguiente. En cierta ocasión un lobo se vistió los hábitos de confesor. Pronto se acercó un león, exclamando: Padre, he despedazado varios animales, pero sólo para mi sustento; he devorado una grey de ovejas; también he matado a un hombre y mantengo en continua guerra a los demás antmales porque son inferiores a $\mathrm{mi}$, ¿̇ qué significa todo esto? exclama el lobo, el confesor. Dado que eres rey, no pasan de ser pequeñas debilidades. Vete tranquflo. Se áleja el leôn $y$ he aqui que se acerca un borriquillo muy humillado
\end{abstract}

11. In fer. III post Dom. I Quadrag. c. II n. 3, t. I, 390-391.

12. In fer II post Dom. II Quadrag. c. II n. 18, t. II, 100-101. 
y compungido, con la cabeza inclinada. $\mathbf{E}$ inmediatamente escucha de la boca del lobo confesor: iOh malvado!, ¿a qué vienes? ¿Acaso ignoras que el número y gravedad de tus ofensas contra mi son tales que merecen la muerte"? ${ }^{13}$.

Ciertamente la expresividad de la fábula no puede ser mayor. Tal vez fuera muy provechoso meditar frecuentemente su significado. La caridad del confesor consciente de su misión sólo ve en cuantos se acercan al confesionario al penitente que le presenta un alma que salvar y para cuya empresa soliciła su colaboración.

Santo Tomás habla muy frecuentemente de la acepción de personas en el confesionario y en la imposición de la penitencia. Pero ¡cuán diversa aplicación hacen del conocimiento de la persona el confesor y el mundo! Ya nos to ha insinuado. "El mundo y los influenciados por su espíritu se esfuerzan en conocer la nobleza de origen, la posición económica y el ambiente de relaciones sociales en que se mueve una persona concreta.

El confesor que vive su ministerio, en cambio, dirige todos sus esfuerzos al conocimiento minúcioso del estado moral del penitente. Trata de saber a la luz de Dios a qué altura se encuentra el querer sincero del hijo de Dios a quien escucha. Se esfuerza en captar a través de las acusaciones la verdadera intención que guía su vida escondida en lo profundo de su ser, que guía su vida, para poner su mano delicadamente, como lo haría Cristo, allí donde estả el mal y restituirle la salud. En su criterio no entran en juego ni la persona física ni elemento alguno humano, sino en la medida en que le ayudan a descubrir la situación moral del penitente. El confesor, desde que. recibe al penitente hasta que le absuelve, es el hombre de Dios, plenamente empapado en el espíritu de Cristo que a todos trataba "cum mansuetudine et magnificentia", que sobre todo fue benigno para con los pobres, mientras que a los ricos les aplicó la justicia en su rigor.

Esa misma caridad dirigirá todo el encuentro sacramental. No es necesario advertir que el reclamo a la consideración de CristoRedentor es continuo: "Considera quid fecerit Christus pro lucran-

13. In fer. II post Dom. II Quadrag. c. II n. 18, t. II, 100-101: In Dom. IV Quadrag. c. IV n. 6, t. II, 83-84; In fer. II post Dom. IV Quadrag. c. II n. 7, t. II, 95; In fer. II post Dom. IV Quadrag: c. II n. 23, t. II, 103. 
dis animis.... Toda su enseñanza pudiéramos resumirla en el principio anteriormente enunciado:

"Volo autem potius peccare per mansuetudinem quam per rigorem, ut sit minister magnificus sicut et Dominus magnifice conơonat" 14.

Y la primera cualidad de la caridad, que como tal sólo se preocupa de la salvación del alma, es la de la adaptación al estado de ánimo y a las condiciones del penitente para hacer más eficaz su cooperación, para conducirle al encuentro personal con el Padre en Cristo. Aduzcamos uno de los ejemplos que tal vez ayudará al confesor a ser constante en los casos difíciles:

"iOh Pastor singular!, por cuántos medios tratas de convertir a Ti aquel alma que el demonio arrebató de entre los que formaban tu colegio. ¡Cuánto cuidado! Estás más preocupado por el alma del traidor, que por tus tormentos. He aquí que primero experimenta la vía del beneficio dándole su Cuerpo y lavándole los pies; llama después al pudor mostrándole que conocía su traición, por lo cual dijo: "En verđad os digo que uno de vosotros me entregará..." ( $M t$. 26,21). Acude al castigo: "El Hijo del hombre sigue su camino como de El está escrito, pero desdichado aquel por quien el Hijo del hombre será entregado. ¡Mejor le fuera no haber nacido! ( $M t$, 26,24). Lo llama compadeciéndose de sí mismo cuando dice: "Ardientemente he deseado comer esta Pascua con vosotros antes de padecer" (LC. 22,14), 1o llama amorosamente porque $\mathbf{S}$. Juan anota que Cristo se turbó cuando dijo esto. $\bar{Y}$ algunos afirman. que el Señor lloró del dolor que le causaba la condenación de Judas. Pero no se doblega esta bestia cruelisima. No se compadece de su Maestro, sino que prepara la emboscada, busca la oportunidad y vive pendiente de cómo cumplir la promesa dada a los fariseos... He aquí un ejemplo para los prelados: El Señor preveia la condenación de Judas, porque de él estaba escrito que le entregaría $\mathbf{y}$, sin embargo, no cesa de corregirle, invitando asi a los prelados a que no cesen de preocuparse de aquellos que consideran perdidos o casi incorregibles" I5.

¡Qué difícil es describir la adaptación de la caridad que, en la humildad del que renuncia como vencido, logra la gran victoria del amor! Sto. Tomás de Villanueva utiliza las relaciones médicoenfermo para describir la actitud, la disposición interna que crea la verdadera caridad en el confesor con relación al penitente. Toda

14. In Dom. IV $A d v$. c. VII n. 2, t. I, 141

15. In fer. $V$ in Coena Domini c. I n. 3, t. II, 225-226. 
su mentalidad nos hace pensar que la consideración del sacerdote como juez tiene más afinidad con el juicio de un médico que examina la enfermedad, que con el juez estatal que comprueba y castiga el delito culpable. Sto. Tomás no ha sufrido la influencia lel concilio Tridentino y se mantiene en la línea tradicional de San Juan Crisóstomo, San Gregorio Nacianceno, San Paciano, etc. ${ }^{16}$. La misión del confesor es ayudar al penitente a realizar una confesión que le restituya la salud perdida por el pecado. La caridad le hará sentirse más médico que juez. Más que confrontar los actos relatados por el penitente con una ley fría, intentará descubrir la intención profunda que mueve su vida, que alimenta la podredumbre de su llaga y proceder como procedería Cristo en este caso concreto. Su vivencia de médico espiritual le infundirá al mismo tiempo un gran respeto por el penitente y una especie de inteligencia puesta al servicio del bien del penitente.

La conducta del confesor no puede convertirse en un obstáculo de la confesión sino en el más fuerte estímulo para frecuentar su celebración. Si las relaciones confesor-penitente son las del médico-enfermo y si el médico se decide a obrar en cada caso concreto según la dolencia de cada enfermo, así el confesor determinará, en conformidad con las circunstancias concretas, cómo ha de intervenir en la búsqueda de una buena confesión. La caridad será buena conductora. Recordemos sus palabras:

\begin{abstract}
"El segundo remedio para los que padecen fiebre es el vómito. Cuando alguien tiene fiebre y se siente a disgusto procura vomitar $e$ inmediatamente se siente aliviado. $Y$ tú, cristiano, si quieres verte libre de la fiebre del alma, arroja de tu corazón los pecados, vomítalos a los pies del confesor. Comienza alguno a vomitar y vosotros, deseosos de su salud, le animais a que lo haga con toda la fuerza y sosteneis su cabeza entre vuestras manos para que no se fatigue. Así tú, oh confesor, si deseas la salud del penitente, socórrele delicadamente, ayúdale en cuanto puedas para que vomite saludablemente, es decir, para que logre una sana. y perfecta confesión" 17 .
\end{abstract}

Es impresionante la insistencia y el amplio margen que da a la intervención del confesor. Cuando hablábamos de la necesidad de

16. S. J. Crisostomo, De sacerdotio II, 2-3 PG. 48, 633-634; S. G. Nacianceno, Orat. 42, 23-24 PG. 36, 484-486; S. Pactano, Paraen. ad Poenitentiam 9 PL. 13, 1.086.

17. In fer. $V$ post Dom. III Quadrag. n. 9, t. II, 49. 
la gracia para la conversión, nos presentaba con tanta viveza la intervención divina que Dios llegaba hasta el limite máximo que le permitía el respeto por la libertad humana. La misma naturaleza de las cosas le imponian límites. De lo contrario tomaria sobre Si la obra total de la conversión, pero sin violentar la libertad humana:

"Hac voce atrahit Deus animam citra coactionem ullam, arreptam tamen" 18 .

Y ahora, hablando de la cooperación del sacerdote, le recuerda que su misión es crear en el alma del penitente un ambiente que como que le coaccione amorosamente a buscar el encuentro con Dios. El confesor tomará sobre sí, para aligerar las dificultades de quien se arrepiente, cuanto la esencia de la conversión y la estructura sacramental le permitan. El confesor está autorizado para emplear cuantos medios estén a su alcance para obtener la conversión, guiado por la caridad y benignidad del Redentor:

"Dios envía confesores y predicadores apostólicos con esta consigna: "Soltadlos y atraédmelos"; Dos cosas ordena: Que sean libertados de los pecados y que sean atraídos a Cristo con amonestaciones $y$ ejemplos. Vean los prelados si liberan, o más bien, atan con abundancia de mandatos y hasta con litigios".

"Ipsam religionem nostram quam paucissimis et magnificentissimis sacramentis Dei misericordia voluit esse libera, quidam servilibus premunt oneribus, ut tolerabilior sit conditio iudoeorum, qui legalibus sacramentis non humanis praescriptionibus subiiciuntur". Por tanto los fieles de la Iglesia han de ser absueltos, mediante el ministerio de los sacerdotes, de los lazos de los pecados, de la perplejidad escrupulosa de algunos y con paternal discreción, prudente consejo y solicito cuidado han de ser llevados a Cristo con amenazas, avisos, ejemplos, exhortaciones, enseñando, arguyendo, amonestando: $y$ si faltan las fuerzas, siguiendo el ejemplo de Cristo, han de llevarlos sobre sus hombros. Si es delicado, débil o tibio, se le ha de tratar con mucha paciencia, benignidad y caridad" 19.

Su misión es crear, no destruir. Sin embargo, lo que en unos edifica en otros destruye. $Y$ ahora expone una nueva idea: La confesión ha de regularse "secundum regulas artis". Fecunda idea que puntualiza más la mentalidad del Santo. Ya el médico cuidadoso proporciona su vigilancia y los medicamentos al estado de salud,

18. In Dom. IV Adv. c. I n. 5, t. I, 118.

19. In Dom. in Palmis c. II n. 7, t. II, 222. 
debilidad o fortaleza del enfermo. No obstante quiere recalcar esta comprensión del confesor que a veces parece disimular un mal menor para evitar un mal mayor y en espera de un bien superior la "regula artis" aconseja proceder de una manera u otra según convenga a la salud del penitente, con to cual lo subjetivo juega un papel importante. El confesor es un "phebotomus" que sabe "laxare et comprimere secundum regulas artis":

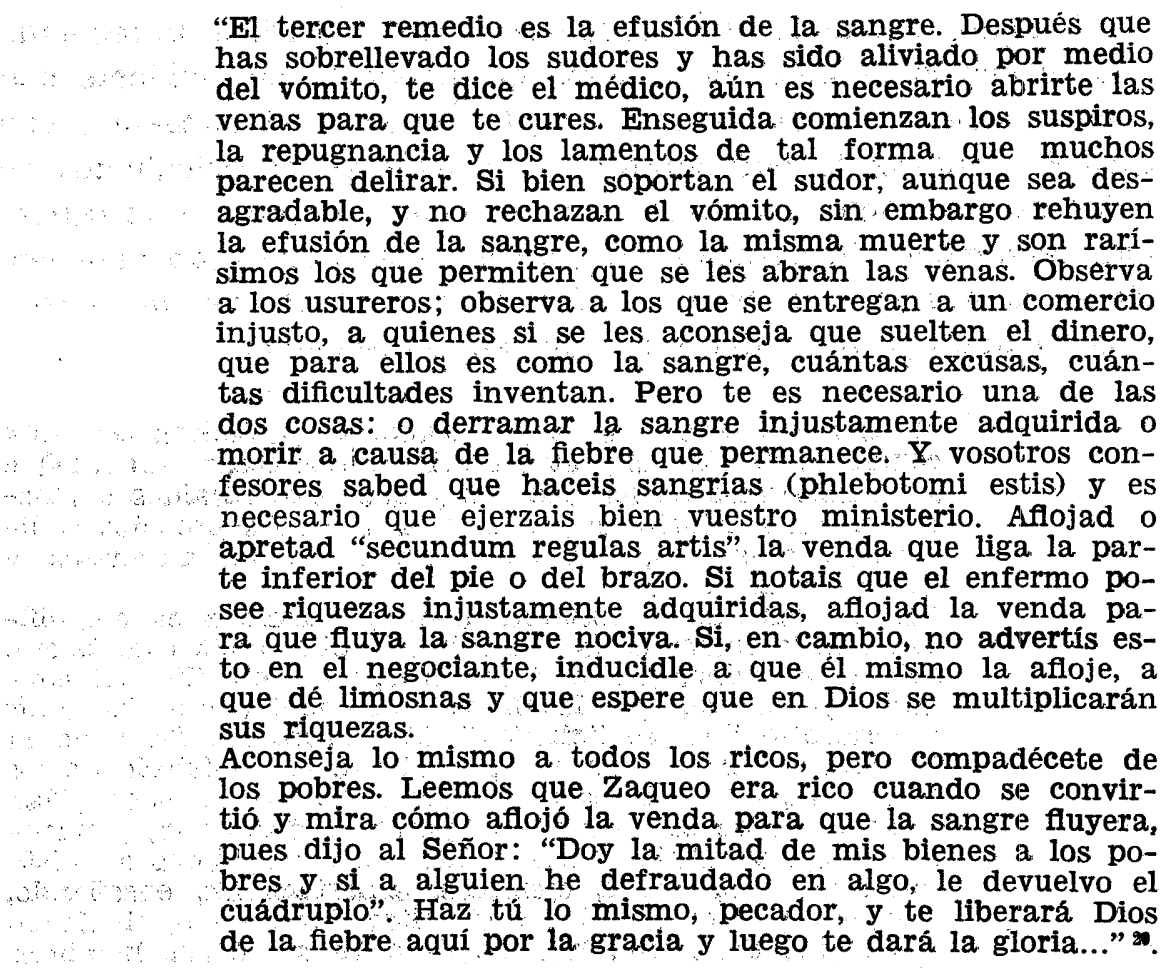

Este texto prueba claramente la acertada idea que tiene Sto. Tomás de Villanueva de la progresividad y dinamismo de la conversión. No ha caído en el error de exigir inmediatamente desde el comienzo el acto pleno, que corresponde a la perfección del amor, a los que en sus inicios experimentan dificultades en la práctica de una virtud. No comprendería una dureza semejante. ¿Acaso Dios se comporta asi en su paciencia infinita? El confesor que ha cap-

20. In fer. $V$ post Dom. III Quadrg. n. 10, t. II, 49-50 
tado esas "regulas artis" no exigirá al grano de trigo, lleno de promesas, que fructifique inmediatamente en la espiga plena. Sabe que debe transcurrir el tiempo debido. Ha de exhortarle y ayudarle a amar más y mostrarle la vía, pero debe esperar con paciencia y soportar que el amor fructifique lentamente. El confesor creará en el penitenie una disposición tal que él mismo perciba, sin necesidad de un tercero, las exigencias de la correspondencia al amor y se sienta obligado a remozar el esfuerzo que le conducirá a la posesión de la virtud perfecta.

El confesor, temeroso de abusar del sacramento, impide a veces celebrarlo en momentos en los que sería más eficaz. Así sucede con los habituados. Se confiesan una y otra vez y nuevamente caen. ¿Qué hacer? ¿Vienen realmente dispuestos a la celebración del sacramento? Trata el problema en diversas ocasiones y en ellas suele reducir las diversas clases de pecadores a dos grandes grupos: Unos que pecan por fragilidad y otros que to hacen por malicia ${ }^{21}$.

Los que pecan por debilidad encuentran su exacta descripción en aquellas palabras del Apóstol: "No hago el bien que quiero sino el mal que no quiero" (Rom. 7,15). Odian el pecado y no obstante pecan. En su fragilidad se ven superados por el vicio, por los malos hábitos. La pasión es una fuerza irresistible que los arrastra ${ }^{22}$. Algunas afirmaciones del Santo sobre este grupo pueden dar origen a confusión. Ha vivido el problema con la misma intensidad con que se nos presenta a nosotros. Se trata de resolver el problema que plantea la incertidumbre del propósito. La dificultad que ofrecen algunos de sus textos ha de ser solucionada en el estudio de su contexto.

Habla de consuetudinarios y recidivos. Habla de varias etapas del pecado: consensus, consuetudo, contemptus ${ }^{23}$. Sin embargo, cuando se plantea el problema de la absolución todos los pecado-

21. In Dom. III Quadrag. c. IV n. 5, 6, 2, p. 27-28; In fer. VI post Dom. I Quadrag. c. I n. 6, t. I, 446-448; In Dom. III Quadrag. c. III n. 6, t. ll, 22-23; In fer. II post Dom. IV Quadrag. c. II n. 2, t. II, 92 ; In Dom. IV Adv. c. II n. 5, t. I, 123-124; In fer. IV post Dom. I Quadrag. c. II n. 16, t. I, 417-418; In fer, IV Cinerum c. II n. 8, t. I, 305.

22. In Dom. III Quadrag. c. IV n. 5, t. II, 27-28; In Dom. I Adv. c. III n. 4, t. I, 23-24,

23. In fer. VI post Dom. IV Quadrag. c. II n. 4, t. II, 116; In fer VI post Dom. IV c. III n. 6, t. II, 132 
res quedan encuadrados en uno de los dos grandes grupos anteriormente indicados.

Refiriéndose a los que pecan por debilidad describe asi lo trágico de su vida. Responden afirmativamente a la Hlamada del Señor. Desean la salud pero no abandonan los vicios y los pecaclos. Lloran sus pecados pero reinciden en los mismos "non tan voluntate, quam veluti quadam necessitate peccantes". Son aquellos que gimen bajo el yugo del pecado y que se ven sometidos a una durísima esclavitud: "non tam miseri quam miserandi". Habla en otras ocasiones de esa especie de necesidad que impulsa a los pecadores a la recaída ${ }^{24}$. No se trata de una necesidad absoluta:

"Necessitate dico, non absoluta, sed de qua dicit Augustinus, quod consuetudo peccandi vertitur in necessitatem" 25.

Tal necesidad no libera de la responsabilidad, pues o que cónsidera obra de muerte al pecado que procede de ella ${ }^{26}$. Tampoco excluye la libertad ${ }^{27}$, pero tales pecadores no son "tam miseri quam miserandi" ${ }^{28}$. Siempre habla de ellos con suma comprensión y benignidad. En realidad, escribe, odian el pecado que cometen. Pecan dominados por la pasión, por la debilidad o por la ignorancia. Aman el bien aunque practican el mal " "ex infirmitate et violentia quadam" ${ }^{29}$. Por eso dice que para ellos "venia facilior est; quia culpa excusationem quamdam habet" 30 .

Ciertamente sus recaídas frecuentes plantean un grave problema en cuanto al propósito. Se puede decir que no son libres en el proponer:

¿...paucissimi sunt qui libera voce respondent: volo; huiusmodi enim voluntatem statim sequitur salus; nam qui sic

24. In Dom. Sexag. c. I n. 2 , t. I, 243-244.

"Quintus gradus est consuetudo inveterata: vertitur in naturam et in miseram necessitatem. Sed dicens: iam cogor ad peccadum, et peccatum adeo est voluntarium ut, si non sit voluntarium, non sit peccatum; ubi autem necessitas, iam non libertas: ergo nec peccatum. Responsio Bernardi: "Libertas non $\tan$ in contingentia quam in voluntate consistit: ubi auten voluntas ibi complacentia". Magna ergo libertas; nam non modicum vis, quod sic vis, ut ideo non possis iam non velle..." (In Dom. V rost Epiph. n. 3, t. I, 197).

25. In fer. VI post Dom. I Quadrag. c. I n. 6, t. I, 447.

26. In fer. VI post Dom. I Quadrag. c. I n. 6, t. I, 447 .

27. In Dom. V post Epiph. n. 3, t. I, 147.

28. In fer. VI post Dom. I Quadrag. c. I n. 6, t. I, 447.

29. In Dom. III Quadrag. c. IV n. 5, t. II, 27.

30. In Dom. III Quadrag. c. IV n. 5, t. II, 27. 
efficaciter vult; facit quod in se est; facienti autem quod in se est, Deus dat gratiam" 31:

Nadie duda de la necesidad del propósito. El problema radica en ver si es posible cuando las recaídas se repiten. Sto. Tomés afirma crudamente la necesidad del primero, pero no excluye la posibilidad del segúndo. Después de sús más tajantes afirmaciones sobre la necesidad del propósito que suele acompañar de algunos ejemplos que inducen a pensar que la recaída es signo de ausencia del auténtico propósito, corrige inmediatamente diciendo que su pensamiento no es ése. Es decir, que admite la posibilidad y coexistencia de las recaidas con la realidad de un verdadero propósito:

\begin{abstract}
"Adviértase que con esto no quiero afirmar que quien recalga en el pecado no haya sido absuelto antes Para obtener la absolución es suficiente el verdadero y firme propósito de abstenerse, aún cuando después, vencido por la pasión, no se abstuviere. De lo contrario ¿quién se salvaria? Definitivamente, pues, si quieres conseguir la salud, prepara tu alma lo mejor que te sea posible haz cuanto está a tu alcance $y$, si recayeres, levántate de nuevo y así tantas veces cuantas recayeres. Bendito sea el señor que,
\end{abstract}

31. In fer. VI post Dom. I Quadrag. c. I n. 6, t. I, 447 : In Dom. Sexag. c. I n. 2, t. I, 243-244.

"Vae misero peccatori captivo, in quo regnat consuetucio peccati!, quam difficile potest ab ea liberari! quam difficile est, ut sui emendationem veraciter proponat et sine fictione! Pro quo nota quod dicitur in Evangelio. Mulier illa Samaritana aquam vitae petit a Domino dicens: Vade, voca virum tuum. Ut quid, Domine? Nonne sine viro poterit recipere aquam vitae? Quid consequentiae habet, aut quae est ita responsio: Da mihi aquam: Voca virum tuum? Nota mysterium; quoniam coetera non quadrant. Cum pecator plorat peccata, mulier venit ad puteum ablutionis, poenitentia sanatur. Sed non sufficit mulier, id est, contritio; adducat virum constantem et robustum, id est, propositum firmum abstinendi de coetero a peccatis, sine quo non portabit aquam in hydria conscientiae suae. Sed o quam multi sunt, qui respondere possunt, etiam dum peccata lacrymantur Domine, non habeo virum. Ita enim est; nam adulterium est illud propositum, quod habent. Vis agnoscere, quod propositum sit legitimum, et quod adulterinum? Vide si vir est conscientiae; quod cognoscitur in duobus; nam primo vir non est alteri nuptus, secundo, vir agit vitam coniugalem; aduiter vero stuprat et vadit. Si propositum est legitimum, nuptum est conscientiae, nam quietat eam; si vero est remorsus intus, iam iurgia miscet, leno est, non est vir. Item, si post confessionem statim mutas propositum et redis, crede tunc animae, quod hunc quem habes non est tuus vir; nam non egit vitam longam cum uxore conscientiae.

Nota tamen in hoc quod si vere proponat, etiamsi iterum post confessionem aliqua victus passione vel ex infirmitate, vel alias peccet, non negamus veram fuisse poenitentiam, ubi lacrymae de corde puro et propositum fuit legitimum, etsi non secuta est correctio. Alias, si peccare recidivante ex fragilitate, non fuit vera eius poenitentia, quis poterit salvus fieri?... (In Dom. $A d v$. c. VII n. 3, t. I, 142). 
viendo: la inclinación y la facilidad con que cae la naturaleza humana, puso al alcance del pecador un remedio tan fácil que pudiera reiterarse fácilmente para no perecer. Gran consuelo es para los pecadores que el Señor ordenara a Pedro que perdonara setenta veces siete": 32 :

Y lo sorprendente es que cuando da esta solución no piensa en un pecador que cae de vez en cuando. Piensa precisamente en los recidivos y habituados, en su salvación.

Conoce la tiranía del vicio y su fuerza arrolladora. Sabe que tales pecadores encuentran grandes dificultades y que el suyo es un "si" débil, que el vicio deja en tal debilidad que la caída se repetirá casi ciertamente. Para consuelo del pecador y orientación del confesor considera natural que recaiga. Mueve al penitente a la lucha contra el pecado, trata de conducirle a las más altas cumbres y, sin embargo, parece decirle: No pretendas demasiado de una vez. El pecado realizó paulatinamente su obra y la conversión se consolidará también progresivamente.

La debilidad de quien inicia el camino de la conversión es tal, que el mayor error, tanto por parte del penitente como del confesor, sería exigirle desde el momento de la absolución la fortaleza de quien hace largo tiempo que vive en estado de gracia. La conversión guarda un paralelismo perfecto con el enfermo que inicia el periodo de convalecencia. No llega a la salud robusta sino después de un largo caminar. Aun cuando en los comienzos de la convalecencia está ya curado, permanece débil. Lo mismo acontece con el propósito fluctuante de quien inicia la conversión:

"¿Yaces en cieno y deseas ser purificado? Levántate del cieno $\mathrm{y}$ te purificará Cristo. Segundo, toma tu lecho en el que yacias y lo que antes era placer, sea ahora peso; echa sobre ti tu pecado, haz penitencia por él, aunque sea levísima, $\mathrm{y}$ anda; adelanta en las virtudes, en las buenas obras; ejercitate en la piedad y serás salvo. Estos son los tres signos de una perfecta sanidad. Cuando falta alguno de ellos no estás completamente sano aunque en cierta manera has sido curado de la enfermedad con sólo levantarte. Permaneces, sin embargo, débil y enfermo y fácilmente recaes, como cuando cesa la fiebre pero no han desaparecido sus efectos" ${ }^{33}$.

El comienzo de la conversión aparece como un estado caótico

32. In fer VI post Dom. Passionis c. III n. 7, t. II, 209.

33. In fer. VI post Dom. I Quadrag. c. I n. 5, t. I, $447-448$. 
en el que la salud y la enfermedad libran una desesperada batalla para conquistar al hombre:

"...licet aliquo modo sis ab aegritudine curatus, surgendo solummodo; tamen debilis et infirmus, facile recidis..." ${ }^{34}$.

Porque tiene esta idea dinámica de la conversión afirma tajantemen é la necesidad del propósito, como es natural. Después explica su afirmación con las siguientes imágenes:

"Contrición y propósito contraen un admirable matrimonio. Si el propósito es sincero llevará una verdadera vidá matrimonial con la conciencia y rechazará la unión con cualquier otra cosa y la conciencia se sentirá tranquila. Y si la tranquilidad no reina en la conciencia es que el propósito no es su marido, si đespués de la confesión cambias el propósito y recaes, cree en tu interior que quien te acompaña no es tu esposo, porque no ha vivido largo tiempo con su esposa, la conciencia".

"Así, por ejemplo, se acerca al confesonario un concubinario y le pregunta el confesor si tiene el propósito de renunciar a su mala vida. Responde: $\mathrm{Me}$ lo he propuesto y me lo propongo. ¿Dónde está la mujer?, pregunta el confesor. En casa, responde el penitente, pero me he propuesto no tocarla. Oh, necio, el propósito que tienes no es tu esposo, es un adúltero de la conciencia. Ten en cuenta, sin embargo, que si alguno hace un verdadero propósito, aunque después de la confesión pecare vencido por la pasión - víctima de la debilidad o por cualquier otra razón, no negamos que su penitencia fuera verdadera cuando hubo arrepentimiento y propósito sinceros, aunque luego no se haya corregido. De lo contrario, si no fuera verdadera la penitencia de aquél que recae por fragilidad, ¿quién se salvaría?..." ${ }^{35}$.

Es digno de notarse, como ya advertimos, que cuando más decididamente afirma la necesidad de un propósito verdadero para recibir la absolución, tanto más recuerde la advertencia que acabamos de leer. Creo que en su mentalidad jamás se debe negar la absolución a aquellos que, recayendo una y otra vez en el pecado, son diligentes en procurar su reconciliación con Dios. Estos poseen la única condición que se les puede exigir: Mantienen vivo el sen-

34. In fer. VI post Dom. I Quadrag. c. I n. 5, t. I, 447-448.

35. In Dóm. IV Adv. c. VII n. 3, t. I, 142-143; In fer. VI post Dom. III Quadrag. c. II n. 5-6, t. II, 623.

Cfr. TER HAAR, De occasionariis et recidivis, Marietti, Taurini 1939, 9495, 256 aduce como argumento de autoridad algunos textos de Sto. Tomás de Villanueva, pero los cita demasiado aisladamente y sacándolos de contexto.

T. RoDríguez, Estudio sobre los escritos de Santo Tomás de Villanueva, Salamanca 1896, 71-89 presenta un esbozo del pensamiento dèl Santo. 
tido del pecado y desean sinceramente liberarse de él ${ }^{36}$. Son aquellos pecadores que podemos considerar descritos en las líneas que siguen:

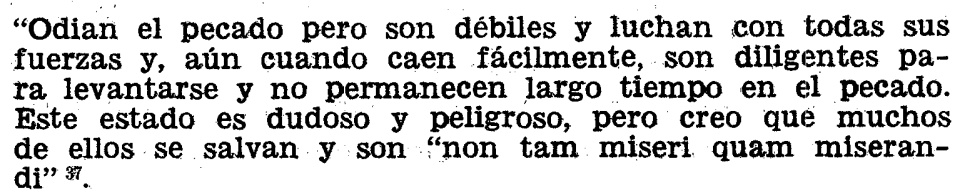

El confesor no podría aumentar la incertudumbre de su suerte negándoles la absolución. Una conducta tan rígida podría ser causa de consecuencias incalculables. Es deber del confesor procurar que en estos casos, más que en ningún otro, la concelebración del sacramento de la penitencia sea una manifestación de la misericordia infinita de Dios y contribuir con ella a destruir la incertidumbre de su estado y labrar la seguridad de su salvación.

Las objeciones más serias contra estas afirmaciones provienen de una de sus homilias del III Domingo de Cuaresma. No obstante, en la misma homilía se encuentra el principio de solución. Cada una de sus afirmaciones debe ser interpretada en el contexto total de la misma. Ciertamente habla de los recidivos, pero es fundamental recordar que el Santo distingue tres clases de recidivos: Recidivos en la culpa, como quien cometido un hurto o un adulterio se confiesa y vuelve a cometerlo; recidivos en la servidumbre del pecado, aquel que, libertado no sólo de la culpa sino también de la esclavitud del pecado, recae "in eamdem et aliam servitutem, exemplum de concubinario vel usurario longi temporis"; recidivo en la infidelidad, aquel que, habiendo recibido la luz de la fe, torna a las tinieblas de la infidelidad o de la herejía ${ }^{38}$. Y la homilía está dedicada al estudio de la segunda clase de recidivos: "De secundo loquimur in isto sermone..." "as. Más concretamente quiere hablar de la pobreza de espíritu y dificultad de conversión de quienes habiendo sido liberados de la esclavitud de la pasión vuelven a caer en ella. Así describe la malicia especial de este pecado:

"No es necesario ponderar cuánta sea la ceguera, el descuido, la malicia, la ingratitud de aquel que se somete de

36. In Dom. III Quadrag. c. II n. 6, t. II, 22-23.

37. In fer. VI post Dom. I Quadrag. c. I n. 4, t. I, 447.

38. In Dom. III Quadra. c. III n. 2, t. II, 18.

39. In Dom. III Quadrag. c. III n. 2, t. II, 18. 
nuevo al pecado después de haber sido liberado por la misericordia de Dios de tanto mal sacándole del poder de las tinieblas y trasladándole al reino del amor. No extraña en aquel que todavia no conoce la esclavitud del pecado ni la paz de la justicia; pero después de haber experimentado ambos estados el cambiar las delicias de la justicia por las espinas del pecado es una gran ceguera y una culpa más grave. Este pecado es digno de todo castigo e indigno de misericordia. Ejemplo: Si un padre rescatara a su hijo de la esclavitud de los turcos con gran suma de dinero y el hijo se entregara de nuevo a la esclavitud jquién se cornpadecería de él? ¿Quién no diria: Que muera el necio en su esclavitud, puesto que asi lo quiere?" "40.

La conversión de éstos es especialmente difícil por su malicia puesto que conociendo ya la servidumbre del pecado no pueden alegar ignorancia; por el desprecio del que, después de haber conocido ambos estados, cambia la satisfacción de la justicia por otros placeres y finalmente por la ingratitud para quien los libertó "misericorditer et potenter". Por su ingratitud y maldad "traduntur in reprobum sensum et quasi contemptores contemnuntur et fiunt pessimi": :

\begin{abstract}
"Corren el peligro de que les suceda espiritualmente cuanto aconteció materialmente con la esposa de Lot, porque es el justísimo castigo de los que miran atrás y recaen: que se conviertan en estatuas, perdido el gusto de lo espiritual, privados de la luz de la razón y del recto juicio. ILa esposa de Lot de persona fue convertida en estatua privada de corazón. La estatua no teme las amenazas del infierno, ni los castigos de Dios, ni la ignominia, nil la infamia... iOh castigo terrible, el mayor después del infierno y tanto más peligroso cuanto menos se siente! pues'viviendo están muertos "sine sensu et sine spiritu". Por esta causa es más difícil su conversión porque no tienen ni dolor, ni contrición, ni sentido de la miseria en que se encuentran" 2 .
\end{abstract}

Así, pues, la negación de la absolución no queda excluida de antemano, pero el uso de medio tan doloroso debe ser muy restringido. Parece que quisiera restringir la negación de la absolución exclusivamente a aquellos que en sus homilías dice que pecan "ex malitia". Y tales "sunt qui non solum faciunt, sed diligunt peccatum: adeo in eis malitia perversa per exercitium peccatorum, et corrupta ratio est..." "43. Tales son aquellos que sepultados en el vicio no

40. In Dom. III Quadrag. c. III n. 2, t. II, 18.

41. In Dom. III Quadrag. c. III n. 2-3, t. II, 18-19.

42. In Dom. III Quadrag. c. III n. 2-3, t. II, 18-20.

43. In Dom. III Quadrag. c. IV n. 5 , t. II, $28 ;$ In fer. VII post Dom. IV Quadrag. c. I n. 4-6, t. II, 110-111. 
sienten su reato ni anhelan la liberación; son obstinados despreciadores de Dios ${ }^{44}$ y el desprecio es la sima más profunda del pecado ${ }^{45}$. Tales son, finalmente, los que libertados de la servidumbre de una pasión se comportan de tal forma que recaen en la misma ${ }^{46}$. Sólo a éstos y sólo mientras se mantienen en tal estado de adhesión se les puede negar la absolución. Mientras haya algún "sensus peccati et confussio de peccato": aún es tiempo oportuno ${ }^{47}$. Aun tratándose de pecadores "ex malitia". procederá negarles la absolución únicamente después de haber intentado excitarlos al dolor por todos los medios posibles. Por delante va la conducta de Cristo con Judas que Sto. Tomás de Villanueva aplica al confesor:,

“¡Oh Pastor singular! ¡Por cuántos medios tratas de convertir a Ti aquel alma que el demonio arrebató de entre los que formaban tu colegio! iCuánto cuidado! Estás más preocupado por el alma del traidor que por tus tormentos. He aqui que primero experimenta la vía del beneficio dándole su Cuerpo y lavándole los pies; llama después al pudor mostrándole que conocia su traición por lo cual dijo: "En verdad os digo que uno de vosotros me entregara...." Acude al castigo: "El Hijo del hombre sigue su camino como de El está escrito; pero iay de aquél por quien el Hijo del hombre será entregado!, Mejor le fuera no haber nacido". Le llama compadeciéndose de sí mismo cuando dice: "Ardientemente he deseado tener esta pascua con vosotros antes de padecer"; le llama amorosamente, porque $\mathbf{S}$. Juan anota que Cristo se turbó cuando dijo esto. $Y$ algunos afirman que el Señor. lloró por el dolor que le causaba la condenación de Judas. Pero no se doblega esta bestia cruelisima; no se compadece de su maestro sino que prepara la emboscada, busca la oportunidad y vive pendiente de cumplir la promesa dada a los fariseos... He aqui un ejemplo para los prelados: El Señor preveía la condenación de Judas porque de él estaba escrito que le entregaria $y$, sin embargo, no cesa de corregirle, invitando asi a los prelados a que no cesen de preocuparse de aquellos que consideran perdidos o casi incorregibles" ${ }^{48}$.

"Por tanto los fieles de la Iglesia han de ser absueltos, mediante el ministerio de los sacerdotes, de los lazos de los pecados, de la perplejidad escrupulosa de algunos y con paternal discreción, prudente consejo y cuidado solicito han de ser llevados a Cristo con amenazas, avisos, ejemplos, ex-

44. In fer. VI post Dom. IV Quadrag. c. II n. 4-5, t. II, 117.

45. In Dom. IV Adv. c. VII n. 4, t. I, 144.

46. In Dom: III Quadrag. c. III n. 2, t. II, 18.

47. "Tempus opportunum est, quando in peccatore est adhuc sensus peccati, et confussio de peccato; sed quando iam sepulta est ratio et iudicium, non aproximabunt, scilicet, ut orent..." (In fer. VI post Dom. IV Quadrag. c. III n. 7, t. II, 133).

48. In fer. V in Coena Domini e. I n. 3, t. II, 225-226; In Dom. Sexag. c. V, n. 26, t. I, 275 . 
hortando, condenando, arguyendo, amonestando; $y$ si faltan las fuerzas, siguiendo el ejemplo de Cristo, cargándolos sobre los hombros; si es delicado, débil o tibio, se le ha de tratar con mucha paciencia, benignidad y caridad" 49.

$Y$ una vez cerciorado de que es obligatorio negarles la absolución ha de comunicárselo en un contexto sincero de caridad. Nada más contrario al ministerio sacerdotal que dejarse llevar del mal humor. La verdadera caridad del confesor, ante la malicia y gravedad del pecado, no se deja dominar de un espíritu de venganza que se desata en palabras, sino que se compadece de la miseria o debilidad del penitente. El confesor que sentirá pesada su obligación de negar la absolución, procurará comunicar y hacer ver su dolor y su obligación al penitente. Con durisimas, quizás las más duras expresiones, recrimina Sto. Tomás al confesor que ante el pecado descarga su mal humor en el penitente:

\begin{abstract}
"La verdadera caridad no se indigna con los pecadores agobiados sino que se apiada de ellos; no se irrita ni los humilla, ni une el azote de su lengua al peso de sus pecados sino que, compadeciéndose de su enfermedad y miseria, se esfuerza por remediar la necesidad del hermano. Este comportamiento es gratísimo a los ojos de Dios, oh hermanos, porque los espíritus crueles serán juzgados cruelmente por Dios, no sólo en el futuro sino ahora ya. Quienes se ensanan excesivamente en los pecados de los otros, por este mismo hecho merecen hacerles experimentar estados semejantes para que aprendan en sí mismos a compadecerse de los demás" ${ }^{50}$.
\end{abstract}

Aun con éstos el sacerdote debe comenzar su obra de acercamiento a Dios, en espera de conducirles a la perfecta comunidad de vida con Dios, tan pronto como brota en ellos ese "sensus peccati et confusio de peccato". Entonces sentirá la necesidad de la intercesión de los santos, comenzarán la cura de su pasión con medicinas contrarias y aptas y se esforzarán por abandonar no sólo el pecado sino también las ocasiones. Pero en medio del fragor de la batalla el gran medio vencedor es la confesión. El sacerdote debe procurar conducirlos a una confesión frecuente de sus pecados, porque es provechosísima la acusación y la humillación frecuente ante Dios. Admite que caerán y recaerán antes de llegar a la salud perfecta, a la resurrección del propósito robusto y firme. La confe-

49. In Dom. in Palmis c. II n. 7, t. II, 322.

50. In Dom in Palmis c. II n. 7, t. II, 322. 
sión es concebida como un medio en la lucha contra la enfermedad y no como el acto cuya celebración pusiera fin a la enfermedad y reintegrara de manera instantánea a la salud perfecta.

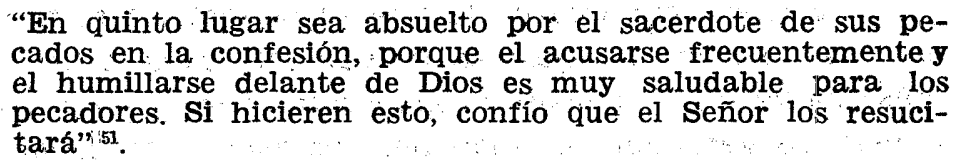

Es lógico en esta aplicación porque cuando tal pecador "cuatriduano" se esfuerza, en la medida de sus posibilidades, por labrar su conversión perfecta, nos encontramos de nuevo ante el caso de quienes pecan por debilidad y no por malicia.

Finalmente hemos llegado al momento de la imposición de la penitencia. También se ha percatado de que ésta puede tener una influencia decisiva en cuanto a la celebración del sacramento en el futuro. Insiste en que deben tenerse presente la humanidad y comprensión del estado del penitente para regular la penitencia que se imponga. A veces el confesor dominado por un espíritu judicial rígido y ante la perspectiva de tal vez numerosos y graves pecados, se desliza insensiblemente por la corriente de la severidad en la imposición de la penitencia. Parece introspeccionarse y quiere juzgar y exigir que el penitente se encuentre frente al pecado en el mismo estado de ánimo en que se encuentra él. Sto. Tomás, gran pastor de almas, santo y riguroso consigo mismo, si se vio asaltado por las dudas y el espíritu de rigidez, supo superarlas racionalmente iluminado por el gran celo de la salvación de las almas. Nos ha legado principios tan claros y formulados con tal seguridad que cierran todo resquicio a la duda:

"Sin embargo el confesor, al imponer la penitencia, consi-
dere no sólo el delito sino también la enfermedad-debili-
dad del penitente y le imponga una penitencia prudente.
Prefiero que peque más por misericordia y mansedumbre
que por rigor. Quiero que sea ministro magnifico al igual
que Cristo perdona con magnificencia. Porque el rigor crea
el peligro de que no cumplan una penitencia que tal vez
aceptaron por temor" 52

Como si la magnificencia de Cristo "minister magnificus" debiera manifestarse en la imposición de la penitencia. Tal magnifi:

51. In fer. VI post Dom. IV Quadrag. c. III n. 9; t. II, 133 .

52. In Dom. IV Adv. c. VII n. 2, t. I, 141. 
cencia encuentra su expresión no en la prevalencia del elemento objetivo, gravedad y número de pecados como norma de la penitencia que se ha de imponer, sino en la recta conjugación de los elementos objetivos con la situación del penitente, elemento personal.

No podemos afirmar que tal criterio esté ausente de nuestras morales. Lo encontramos en ellas al igual que otros principios sabios que nuestro espíritu legalista y; tal vez egoísta, condena al más cruel olvido. Tal vez este olvido encuentre también un fundamento en que tales normas son presentadas frecuentemente por los manuales como excepciones a la norma general. Sto. Tomás, en cambio, considera necesario que formen parte del principio general. Tal vez la norma directiva en cuanto a la imposición de la penitencia sea uno de los casos que más fielmente indican el espíritu de la predicación de Sto. Tomás y su esfuerzo por integrar en unidad armónica y vital lo subjetivo y lo objetivo. Como acabamos de ver lo subjetivo parece ocupar el primer puesto cuando se trata de determinar la penitencia apropiada para cada penitente. No olvida ni desprecia lo objetivo, pero sus exigencias son interpretadas y satisfechas según aconseje lo subjetivo, las disposiciones íntimas del recién convertido y su estado de debilidad. Siempre que peligre la salud del penitente, lo objetivo y matemático en sus exigencias deberá participar de la flexibilidad, de la magnificencia y del amor salvífico de Cristo que tomó sobre sus hombros la oveja perdida. Así, pues, la flexibilidad aconsejada por la debilidad del convertido debe regular la exactitud inflexible de lo objetivo y con la generosidad del ministro magnífico que fue Cristo. No es la fría consideración de lo normativo de la ley la que ha de determinar la penitencia, sino el arte pastoral que, vivificada, por el amor, procura conducir a las almas a la consecución del mayor bien posible en cada momento.

Es una mentalidad constante y firmemente arraigada en la conciencia del santo arzobispo. No rehúye las objeciones, sino que se las plantea a si mismo. Sabe que la absolución destruye la culpa, pero que la pena permanece y que si no satisface por ella en la tierra, será necesario satisfacer en el purgatorio. No obstante, "considero mejor, dice, enviar las almas al purgatorio por imponerlas una penitencia leve que exponerlas al peligro de condenarse imponiéndoles una grave" ${ }^{53}$.

53. Nola autem ut in poenitentiis iniungendis plus aequo severior sis. 
No hay pelilgro de laxismo. Al mismo tiempo que reclama esa benignidad en la penitencia, también vindica que sea "prudente". $Y$ lo será cuando obtenga la armonia entre lo objetivo y 10 subjetivo. La penitencia prudente debe reunir, según sus mismas palabras una "moderación tal del rigor que su levedad no cree el peligro de despreciar la gravedad del pecado, ni su gravedad exponga al peligro de no cumplirla" ${ }^{54}$. ¿Cómo aplicar en la prástica esta apreciable orientación?:

"Según mi juicio lo conseguirás : imponiendo una penitencia fácil y aconsejando otra rigurosa. Pero hazlo de tal forma que apliques también la eficacia del sacramento a la penitencia aconsejada" 55 .

Lo objetivo sigue señalando la meta a conseguir on la perfección progresiva de la conversión, mientras que lo subjetivo determina lo más propiado a la debilidad del nuevo convertido en el mo-

Dictum Domini Salvator is memorare: Allioant onera gravia, et importabilia et imponunt in humeros hominum: digito autem suo nolunt ea movere. Unde et nunc ad Apostolos ait: Solvite et sinite abire. Ac si dicat: non poenitentia eos gravetis, non austeritate terreatis; nam in actione poenitentiae non tam attenditur quantitas rigoris aut temporis, quam doloris. Contritio peccatum tollit; gemitus et lacryma crimen abluit: peccatorem sacerdotis absolutio solvit; exterior autem poena; et de peccato sumit iustam vindictam, et peccatori affert medicinam: Cor contritum et humiliatum Deus non despicit. Exterior poena quae in sacramento non imponitur, sed voluntarie assumitur, si adsit; bona est; sed non semper ipsa sanat aut satisfacit, nisi quatenus ex corde contrito nascitur. Certe in Petro non lego nisi lacrymas, in Magoalena, in Publicano, in rege adultero. Cor contritum et humiliatum, Deus, non despicies; corpus autem 'afflictum non ita semper. Phaerisaeus ieiunabat bis in sabbato, sed non in hoc iustificatum apparuit. Non dico hoc quia exteriorem poenitentiam, etiam voluntariam, non approbem, sed quia interior dolor placet... Confitentis adversum se iniustitiam suam, ipse peccati impietatem remittit; qui peccata sua eleemosynis redimit, quia saccum et cinerem sternit, quia humiliat in ieiunio animam suam, et orationem fundit coram Altissimo,

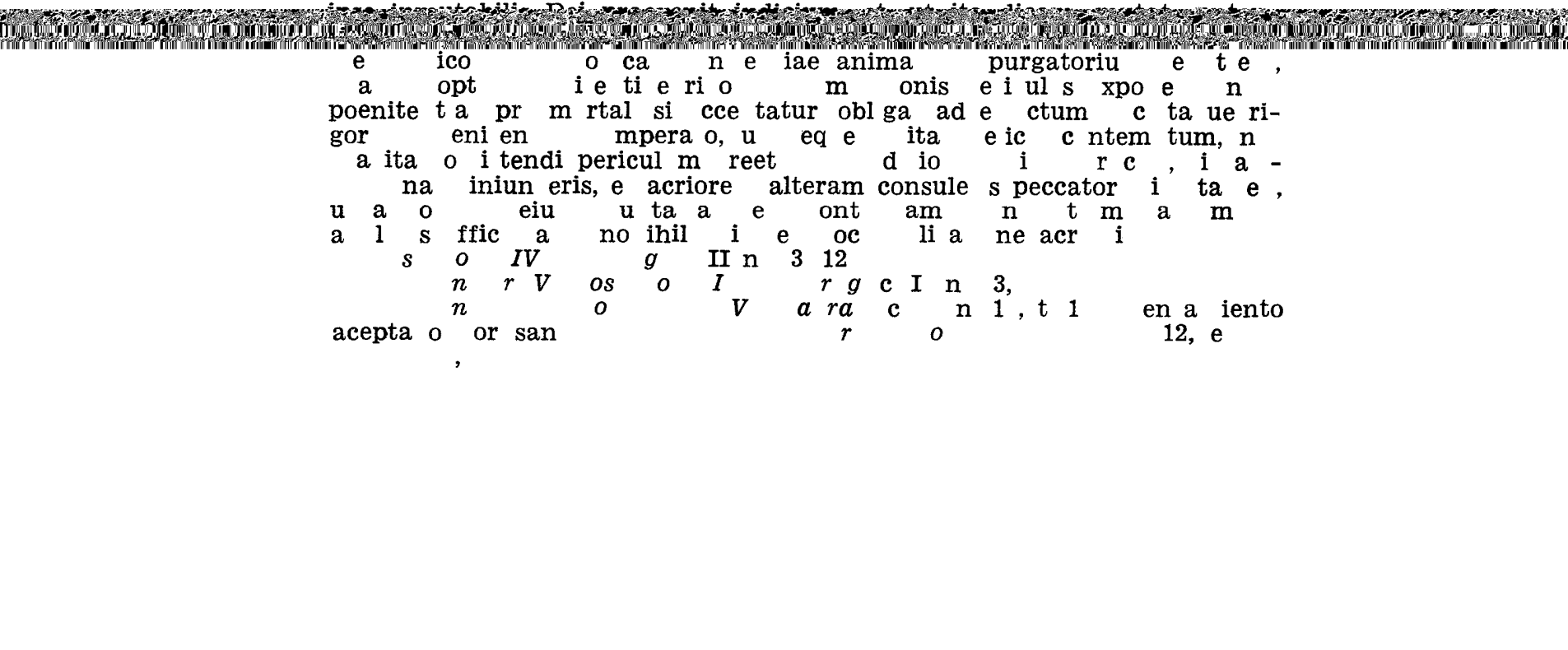


